\title{
Evaluation of the Relationship Between Transcutaneous Bilirubin Measurement and Total Serum Bilirubin in Neonatal Patients Followed for Jaundice
}

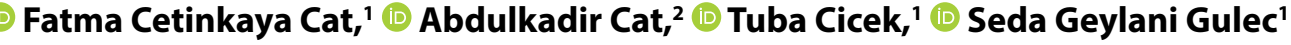 \\ 'Department of Child Health and Diseases, Istanbul Health Sciences University, Gaziosmanpasa Training and Research Hospital, \\ Istanbul, Turkey \\ 2Department of Medical Biochemistry, Istanbul Health Sciences University, Gaziosmanpasa Training and Research Hospital, \\ Istanbul, Turkey
}

\begin{abstract}
Objectives: Jaundice is a physiological condition caused by hyperbilirubinemia, which is common in neonatal period. However, severe hyperbilirubinemia can cause kernicterus, which is a serious condition that leads to neurological problems. In this study, we aimed to investigate whether it is safe to use transcutaneous bilirubin (TCB) instead of blood for the evaluation of jaundice by comparing TcB measurement with standard total serum bilirubin (TSB) measurement values.

Methods: A total of 105 term and early term infants with gestational ages between 37 and 42 weeks were included in the study. MBJ20 TcB measuring device was used for TCB measurement. TcB was measured from the forehead and sternum. To evaluate the relationship between TCB measurements and TSB measurements, we performed Pearson correlation, Spearman correlation, linear regression analysis, and Bland-Altman analysis in which we evaluated the scatter plot of the differences between the average values of the measurements.

Results: There was a positive and statistically significant correlation between TCB forehead and TSB measurements and TcB sternum and TSB measurements $(p<0.001)$. Linear regression analysis showed a positive directional correlation between TcB forehead and TSB measurements $\left(R^{2}=0.85\right)$ and TcB sternum and TSB measurements $\left(R^{2}=0.87\right)$. Bland-Altman analysis showed a good consistency between TSB and TCB forehead measurement methods (mean difference: 0.39 $\pm 1.46,95 \%$ Cl: [-2.47]-[3.26]), and between TSB and TcB sternum measurement methods (mean difference: 0.49 \pm 1.32 95\% Cl: [-2.1]-[3.07]).

Conclusion: As a result of our study, we found that TCB measurement can be reliable instead of taking blood for jaundice evaluation.

Keywords: Jaundice; neonate; serum bilirubin; trancutaneous bilirubin.

Please cite this article as "Cetinkaya Cat F, Cat A, CicekT, Geylani G. Evaluation of the Relationship Between Transcutaneous Bilirubin Measurement and Total Serum Bilirubin in Neonatal Patients Followed for Jaundice. Med Bull Sisli Etfal Hosp 2021;55(2):262-267".
\end{abstract}

$\mathrm{N}$ eonatal jaundice is one of the most common conditions in newborns. ${ }^{[1]}$ This situation can be seen in approximately $60 \%$ of term babies and $80 \%$ of preterm babies. ${ }^{[2]}$
Neonatal jaundice is a normal physiological condition that usually occurs in the transition period after birth. It is also not a singular disease, but a physical finding associated

Address for correspondence: Fatma Cetinkaya Cat, MD. Istanbul Saglik Bilimleri Universitesi Gaziosmanpasa Egitim ve Arastirma Hastanesi, Cocuk Sagligi ve Hastaliklari Klinigi, Istanbul, Turkey

Phone: +90 5064964628 E-mail: fatoscetinkaya14@hotmail.com

Submitted Date: January 08, 2020 Accepted Date: April 13, 2020 Available Online Date: July 02, 2021

${ }^{\circ}$ Copyright 2021 by The Medical Bulletin of Sisli Etfal Hospital - Available online at www.sislietfaltip.org

OPEN ACCESS This is an open access article under the CC BY-NC license (http://creativecommons.org/licenses/by-nc/4.0/). 
with many possible etiologies. Severe neonatal jaundice is considered pathophysiological. Jaundice reflects the accumulation of the yellow-orange pigment bilirubin in the skin, sclera, and other tissues. It does not imply any particular causation. Therefore, preventive and therapeutic approaches to pathophysiological neonatal jaundice or hyperbilirubinemia are typically not specific. ${ }^{[3]}$ Management of neonatal jaundice aims to prevent kernicterus that can result from high levels of unconjugated bilirubin. Kernicterus is a serious condition and can cause permanent damage. People with kernicterus typically have dyskinetic tetraplegic cerebral palsy, bilateral sensorineural hearing loss, and often upward gaze restriction. ${ }^{[4]}$

In the 2004 American Academy of Pediatrics Subcommittee on Hyperbilirubinemia guideline, total serum bilirubin (TSB) or transcutaneous bilirubin (TcB) measurement is recommended before discharge from the maternity hospital to evaluate the risk of subsequent severe hyperbilirubinemia in all newborns. ${ }^{[5]}$ Although TSB measurement is still the standard in the evaluation of neonatal jaundice, it requires a venous or heel prick blood sampling, which is an invasive and painful procedure ${ }^{[6]}$ Although the risks associated with blood sampling are considered low, the possibilities of complications such as iatrogenic anemia, puncture site infection, bacteremia, and osteomyelitis cannot be excluded in repeated sampling. ${ }^{[7]} \mathrm{TCB}$ meters estimate total serum or plasma bilirubin using multiwavelength spectral reflection from the skin surface. ${ }^{[8]}$

There are studies showing that the widespread use of $\mathrm{TCB}$ or TSB measurements in jaundice screening reduces the rate of newborns with severe hyperbilirubinemia, the rate of hospital readmission for phototherapy, and the number of babies receiving phototherapy. ${ }^{[9-11]}$ However, due to the bleaching of the skin, the accuracy of TcB during phototherapy is lower. Therefore, TCB measurement is not reliable in babies receiving phototherapy. ${ }^{[12-14]}$ There are significant differences between devices that measure $\mathrm{TCB}$. If TCB will be used instead of TSB measurement in the clinic, the compatibility of the values measured by the new device with the TSB values should be compared, and its accuracy should be ensured. ${ }^{[15]}$

In our study, we aimed to investigate whether it would be safe to use TcB measurement instead of blood collection for jaundice evaluation, by comparing TCB measurement, which is a non-invasive, easy, fast and cheaper method, and TSB measurement values, which is the standard method, in patients with suspected neonatal jaundice.

\section{Methods}

In this study, a total of 105 newborns, including babies born at the University of Health Sciences between Feb- ruary 1, 2019, and May 1, 2019, and followed up with the mother before discharge and babies who were followed up in the routine newborn outpatient clinic, were included in the study. Verbal and written information was given to the families of each patient included in the study, and verbal and written consents were obtained from each family. This study was approved by the ethics committee. Term and near-term babies with gestational ages between 37 and 42 weeks were included in the study. Newborns who were clinically healthy except for hyperbilirubinemia, with no detectable pathology, no significant intrapartum and postpartum complications, and no $\mathrm{ABO}$ and/or Rh hemolytic disease were included in the study. Babies who were older than 15 days postnatally, had skin disease, had received phototherapy before, and received exchange transfusion were not included in the study. MBJ20 TcB measurement device was used for TcB measurement. Three measurements were made from the forehead and sternum in each patient and the average value indicated by the device was taken. TcB measurement was performed during bilirubin measurement of newborns scheduled for postpartum discharge or in cases with clinical jaundice during postpartum follow-up. TCB measurement was made within $\pm 10 \mathrm{~min}$ of blood collection for TSB measurement. TSB levels were measured with spectrophotometric method in biochemistry autoanalyzer (Beckman Coulter, AU680) from serum samples.

\section{Statistical Analysis}

Statistical analyzes were performed using the Statistical Package for the Social Sciences (version 11, Chicago, IL, USA) software program. Data were given as mean, standard deviation (SD), minimum, maximum, and percentage. Depending on the distribution of correlations between variables, Pearson or Spearman correlation tests were used. Statistical significance limit was $p<0.05$ and two sided. Pearson or Spearman correlation tests can be a weak indicator for predicting the relationship between two diagnostic tests. Therefore, we used linear regression and Bland-Altman analysis to evaluate the variability between TSB and TCB measurements. The confidence interval (CI) for the mean difference between measurements was given as a $95 \% \mathrm{Cl}$. Significance level was accepted as $5 \%$. In the Bland-Altman analysis, the limits of agreement were defined as the mean of the differences \pm 1.96 SDs.

\section{Results}

The study was conducted with a total of 105 newborns (44 [41.9\%] females and 61 [58.1\%] males). Maternal ages range from 16 to 46 , with $26(24.8 \%)$ being primiparous cases and $79(75.2 \%)$ being multiparous cases. The mean 
gestational age of the cases was 38.6 \pm 1 (range: 37-42 weeks) weeks. The mean birth weight was $3275 \pm 447 \mathrm{~g}$ (distribution: 2355-4480 g). The number of babies born by spontaneous vaginal delivery was $48(45.1 \%)$, and the number of babies born by cesarean section was 57 (54.3\%). The number of cases who were discharged and had their bilirubin measured (coming from home) during outpatient clinic control was 26 (24.8\%), and the number of newborns who were followed up after birth in the mother's side was 79 (75.2\%).

TcB forehead levels varied between 4.2 and $17.6 \mathrm{mg} / \mathrm{dl}$, with an average value of $9.16 \pm 2.95 \mathrm{mg} / \mathrm{dl}$. TcB sternum levels varied between 3.5 and $18.3 \mathrm{mg} / \mathrm{dl}$ with an average value of $9.25 \pm 3.32 \mathrm{mg} / \mathrm{dl}$. TSB levels varied between 2.2 and 19.2 $\mathrm{mg} / \mathrm{dl}$, with an average value of $8.77 \pm 3.64 \mathrm{mg} / \mathrm{dl}$ (Table 1 ).

Whether the relationship between the relevant parameters is statistically significant or not was evaluated by the Pearson correlation coefficient, considering each group separately. There was a very strong (92.2\%) and statistically significant positive correlation between TSB levels and TcB forehead measurements $(p<0.001)$. There was a very strong positive $(93.2 \%)$ and statistically significant correlation between TSB levels and TCB sternum measurements $(p<0.001)$. There was a very strong $(95.7 \%)$ and statistically significant positive correlation between TCB forehead and TcB sternum measurements $(p<0.001)$ (Table 2$)$.

Table 1. TcB forehead, TCB sternum, and TSB measurement values of the cases

\begin{tabular}{lccc}
\hline & Average $(\mathbf{m g} / \mathbf{d l})$ & Min-Max & SD \\
\hline TcB forehead & 9.16 & $4.2-17.6$ & 2.95 \\
TcB sternum & 9.25 & $3.5-18.3$ & 3.32 \\
TSB & 8.77 & $2.2-19.2$ & 3.64 \\
\hline
\end{tabular}

TcB: Transcutaneous bilirubin; TSB: Total serum bilirubin.

Table 2. TCB forehead, TCB sternum, and TSB levels correlation

\begin{tabular}{cccc}
\hline & TcB forehead & TcB sternum & TSB \\
\hline $\begin{array}{ccc}\text { TcB forehead } \\
r\end{array}$ & 1 & 0.957 & 0.922 \\
$p$ & & 0.000 & 0.000 \\
TcB sternum & & & \\
$r$ & 0.957 & 1 & 0.932 \\
$p$ & 0.000 & & 0.000 \\
TSB & & & \\
$r$ & 0.922 & 0.932 & 1 \\
$p$ & 0.000 & 0.000 & \\
\hline
\end{tabular}

r: Pearson correlation coefficient; TcB: Transcutaneous bilirubin; TSB: Total serum bilirubin.
Table 3. Correlation of TSB with TCB forehead and TCB sternum measurement intervals

\begin{tabular}{lccccc}
\hline & \multicolumn{5}{c}{ TSB } \\
\cline { 2 - 6 } & $\mathbf{n}$ & $\begin{array}{c}\text { Average } \\
\text { (mg/dl) }\end{array}$ & SD & $\mathbf{r}_{\mathbf{s}}$ & $\mathbf{P}$ \\
& & & & & \\
\hline TcB forehead (mg/dl) & & & & & \\
$\quad<5$ & 14 & 4.55 & 0.81 & 0.69 & 0.007 \\
$5-10$ & 51 & 8.30 & 1.32 & 0.80 & 0.001 \\
$10-15$ & 37 & 11.8 & 1.22 & 0.78 & 0.001 \\
$>15$ & 3 & 15.2 & 1.41 & 0.50 & 0.67 \\
TcB sternum (mg/dl) & & & & & \\
$\quad<5$ & 12 & 4.2 & 0.30 & 0.96 & 0.001 \\
$5-10$ & 49 & 7.7 & 1.46 & 0.83 & 0.001 \\
$10-15$ & 42 & 12.4 & 1.51 & 0.84 & 0.001 \\
$>15$ & 2 & 17.1 & 1.69 & 1 & - \\
\hline
\end{tabular}

$r_{s}$ : Spearman correlation coefficient; TcB: Transcutaneous bilirubin; TSB: Total serum bilirubin.

When we compared the TCB forehead and sternum levels with TSB levels separately at the measurement ranges of $<5,5-10,10-15$, and $>15 \mathrm{mg} / \mathrm{dl}$, respectively, the values below $15 \mathrm{mg} / \mathrm{dl}$ showed a statistically significant correlation with TSB levels $(p<0.05)$. Although the number of patients in the group with TCB forehead level measurement range $>15 \mathrm{mg} / \mathrm{dl}$ was not sufficient, a statistically significant correlation was not observed $(p>0.05)$. Statistical analysis could not be performed due to the insufficient number of patients in the group with TcB sternum level measurement range $>15 \mathrm{mg} / \mathrm{dl}$ (Table 3 ).

When we evaluated the linear variability between TSB and TCB (forehead and sternum) measurements using linear regression analysis, a positive linear relationship between the methods was found (Figs. 1 and 2).

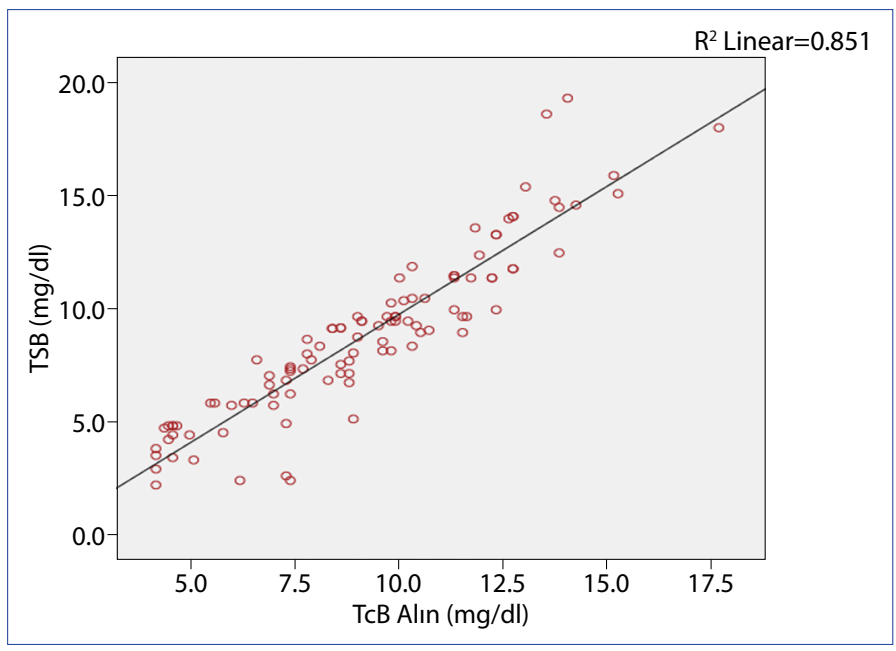

Figure 1. Linear regression analysis between TSB and TCB forehead measurements $\left(R^{2}=0.85\right)$. 


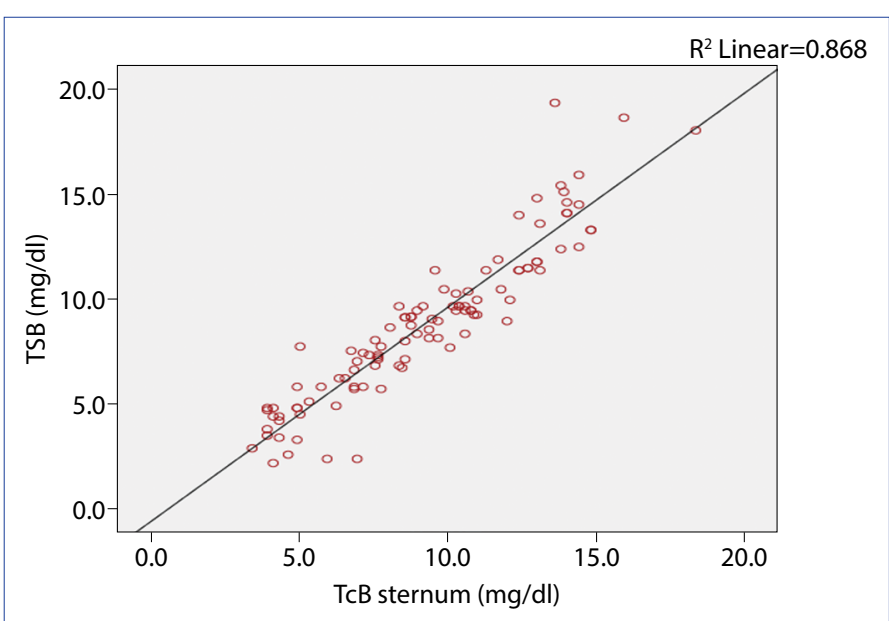

Figure 2. Linear regression analysis between TSB and TCB sternum measurements $\left(R^{2}=0.87\right)$.

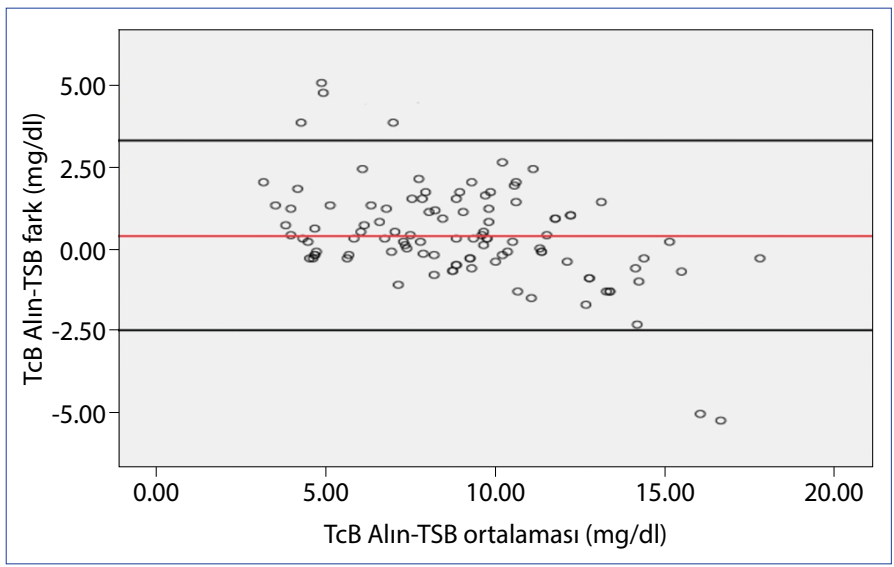

Figure 3. Bland-Altman analysis between TSB and TCB forehead measurement methods (average difference: 0.39 $\pm 1.46,95 \% \mathrm{Cl}$ : [-2.47][3.26], upper limit: 3.26, lower limit: -2.47).

In the Bland-Altman analysis, where we evaluated the scatter plots of the differences between the average measurements obtained from the TSB and TCB (forehead and sternum) measurement methods, we found a strong consistency between the two methods (Figs. 3 and 4).

\section{Discussion}

Most of the newborn babies with an age of $\geq 35$ gestational weeks have some degree of jaundice in the 1st day after birth. ${ }^{[16]}$ Neonatal jaundice is generally not harmful and is a self-limiting condition. However, very high levels of bilirubin, a condition called kernicterus, can cause permanent brain damage. Therefore, it is important to diagnose neonatal jaundice and to manage it appropriately. ${ }^{[17]} \mathrm{TcB}$ measurement is widely used to measure bilirubin levels for screening in newborns. We conducted a prospective correlation study with 105 newborns to examine the correlation of TCB (forehead and sternum), which are non-invasive,

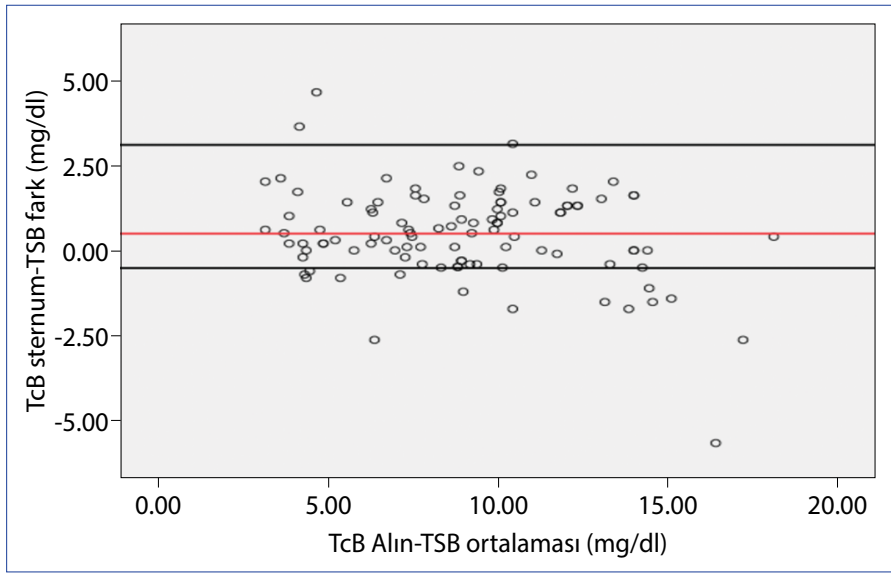

Figure 4. Bland-Altman analysis between TSB and TCB sternum measurement methods (average difference: 0.49 $\pm 1.32, \% 95 \mathrm{Cl}$ : [-2.1][3.07], upper limit: 3.07, lower limit: -2.1 ).

easy, fast, and cheaper methods in detecting hyperbilirubinemia, and TSB measurements, and to evaluate its accuracy as a screening tool.

In our study, a positive very high level of statistically significant correlation between TSB levels and TcB forehead measurements was found $(r=0.92)(p<0.001)$, a positive very high level of correlation between TSB levels and TCB sternum measurements $(r=0.93)(p<0.001)$, and a positive very high level of correlation between TcB forehead and TcB sternum measurements $(r=0.95)(p<0.001)$ was found. When we compared TcB (forehead and sternum) levels with TSB levels according to measurement ranges, we found a statistically significant correlation in groups with TcB levels lower than $15 \mathrm{mg} / \mathrm{dl}(\mathrm{p}<0.05)$. In a study conducted by Gunaseelan et al. with 400 newborns whose gestational ages were older than 35 weeks, they compared the TcB sternum measurements with the TSB measurements and found a significant correlation in between $(p<0.001)$. ${ }^{[18]}$ Likewise, Ho et al. found a significant correlation between TcB measurements and TSB measurements in term or near-term newborns $(p<0.001){ }^{[19]}$ In Maisels et al.'s and Rubaltelli et al.'s studies, they stated that there was a decrease in sensitivity and an increase in specificity at higher TcB cutoff measurement levels. ${ }^{[2,21]}$ Furthermore, Maisels et al. stated that when the TSB measurement values exceeded $15 \mathrm{mg} / \mathrm{dl}$, the number of false-negative readings increased. ${ }^{[20]}$ Likewise, Ho et al. found a significant correlation between TcB measurements and TSB measurements in term or near-term newborns $(p<0.001) .^{[19]}$ In Maisels et al.'s and Rubaltelli et al.'s studies, they stated that there was a decrease in sensitivity and an increase in specificity at higher TcB cutoff measurement levels. ${ }^{[20,21]}$ Also, Maisels et al. stated that when the TSB measurement values exceeded $15 \mathrm{mg} / \mathrm{dl}$, the number of false-negative readings 
increased. ${ }^{[20]}$ Likewise, Ho et al. found a significant correlation between TCB measurements and TSB measurements in term or near-term newborns $(p<0.001) .{ }^{[19]}$ In Maisels et al.'s and Rubaltelli et al.'s studies, they stated that there was a decrease in sensitivity and an increase in specificity at higher TcB cutoff measurement levels. ${ }^{[20,21]}$ Also, Maisels et al. stated that when the TSB measurement values exceeded $15 \mathrm{mg} / \mathrm{dl}$, the number of false negative readings increased ${ }^{[20]}$ Likewise, Ho et al. found a significant correlation between TCB measurements and TSB measurements in term or near-term newborns $(p<0.001){ }^{[19]}$ In Maisels et al.'s and Rubaltelli et al.'s studies, they stated that there was a decrease in sensitivity and an increase in specificity at higher TcB cutoff measurement levels. ${ }^{[20,21]}$ Also, Maisels et al. stated that when the TSB measurement values exceeded $15 \mathrm{mg} / \mathrm{dl}$, the number of false-negative readings increased. ${ }^{[20]}$ To evaluate TCB and TSB measurement costs, $\mathrm{McClean}$ et al. compared the costs of these two screening methods in hospitals and urban and rural communities. As a result of their study, they showed that TCB measurement reduced nurses' screening time, provided immediate results at the bedside, improved access to screening, and reduced total program cost. They stated that savings in the hospital with TcB screening were associated with reductions in nursing time and laboratory costs, while savings in the community program were associated with reductions in travel time, laboratory costs, and mileage. ${ }^{[22]}$ One of the weaknesses of our study was that the lack of correlation between TSB and TcB measurements in preterm babies, babies with low birth weight, dark skin color and who were receiving phototherapy in our study, because these babies were not included in the study. Statistical comparison could not be made since there was not enough patient number in the group with TcB level higher than 15 $\mathrm{mg} / \mathrm{dl}$.

\section{Conclusion}

Although TSB measurement is standard in the evaluation of neonatal jaundice, it is an invasive, painful procedure that requires a blood sample. In our study, we found a significant correlation between TCB (forehead and sternum) measurements and TSB measurements. We think that TCB measurement is a fast, safe, non-invasive, and low-cost screening test that can help to minimize invasive TSB tests and determine neonatal jaundice. Although devices that measure TcB levels reliably estimate bilirubin levels, none of the original guidelines recommend using TCB measurements as an indicator for phototherapy initiation. It is important to note that TCB is only a screening tool, and verification with TSB should be considered especially in high-risk newborns.

\section{Disclosures}

Ethics Committee Approval: This study was approved by Taksim Training and Research Hospital Clinical Research Ethics Committee (10.04.2019/51).

Peer-review: Externally peer-reviewed.

Conflict of Interest: The authors have no conflict of interest.

Authorship Contributions: Concept - F.C., A.C., T.C.; Design F.C., A.C., T.C.; Supervision - F.C., A.C., S.G.; Materials - F.C., T.C.; Data collection \&/or processing - F.C., T.C.; Analysis and/or interpretation - F.C., A.C., S.G.; Literature search - F.C., A.C., S.G.; Writing - A.C., F.C.; Critical review - A.C., F.C., T.C.

\section{References}

1. Çayönü N, Bülbül A, Uslu S, Bolat F, Güran Ö, Nuhoğlu A Indirect hyperbilirubinemia in newborn infants change over the last decade. Sisli Etfal Hastan Tip Bul 2011;45:85-93.

2. Rizvi MR, Alaskar FM, Albaradie RS, Rizvi NF, Al-Abdulwahab K. A novel non-invasive technique of measuring bilirubin levels using bilicapture. Oman Med J 2019;34:26-33. [CrossRef]

3. Cohen RS, Wong RJ, Stevenson DK. Understanding neonatal jaundice: a perspective on causation. Pediatr Neonatol 2010;51:143-8. [CrossRef]

4. Rennie JM, Beer J, Upton M. Learning from claims: hyperbilirubinaemia and kernicterus. Arch Dis Child Fetal Neonatal Ed 2019;104:F202-4. [CrossRef]

5. American Academy of Pediatrics Subcommittee on Hyperbilirubinemia. Management of hyperbilirubinemia in the newborn infant 35 or more weeks of gestation. Pediatrics 2004;114:297316. [CrossRef]

6. Alsaedi SA. Transcutaneous bilirubin measurements can be used to measure bilirubin levels during phototherapy. Int J Pediatr 2018;2018:4856390. [CrossRef]

7. Oldak D, García G, Gonzalez EE, Aillon E, Falcon JC, Ayala E, et al. Reproducibility of BiliCare ${ }^{\mathrm{TM}}$ transcutaneus bilirrubin meter in Mexican newborns. Int J Pediatr 2019;2019:3812152. [CrossRef]

8. Hussain AS, Shah MH, Lakhdir M, Ariff S, Demas S, Qaiser F, et al. Effectiveness of transcutaneous bilirubin measurement in managing neonatal jaundice in postnatal ward of a tertiary care hospital in Pakistan. BMJ Paediatr Open 2017;1:e000065. [CrossRef]

9. Kuzniewicz MW, Escobar GJ, Newman TB. Impact of universal bilirubin screening on severe hyperbilirubinemia and phototherapy use. Pediatrics 2009;124:1031-9. [CrossRef]

10. Eggert LD, Wiedmeier SE, Wilson J, Christensen RD. The effect of instituting a prehospital-discharge newborn bilirubin screening program in an 18-hospital health system. Pediatrics 2006;117:e855-62. [CrossRef]

11. Petersen JR, Okorodudu AO, Mohammad AA, Fernando A, Shattuck KE. Association of transcutaneous bilirubin testing in hospital with decreased readmission rate for hyperbilirubinemia. Clin Chem 2005;51:540-4. [CrossRef]

12. Tan KL, Dong F. Transcutaneous bilirubinometry during and after 
phototherapy. Acta Paediatr 2003;92:327-31. [CrossRef]

13. Ozkan H, Oren H, Duman N, Duman M. Dermal bilirubin kinetics during phototherapy in term neonates. Acta Paediatr 2003;92:577-81. [CrossRef]

14. Casnocha Lucanova L, Matasova K, Zibolen M, Krcho P. Accuracy of transcutaneous bilirubin measurement in newborns after phototherapy. J Perinatol 2016;36:858-61. [CrossRef]

15. Çoban A, Türkmen M, Gürsoy T. Transkutan Bilirubin Ölçümü. In: Yenidoğan Sarılıklarında Yaklaşım, İzlem ve Tedavi Rehberi. Türk Neonatoloji Derneği; 2014. p. 14. Available at: http://www.neonatology.org.tr/wp-content/uploads/2016/12/sarilik.pdf. Accessed Apr 14, 2021.

16. Kaplan M, Bromiker R. Variation in transcutaneous bilirubin nomograms across population groups. J Pediatr 2019;208:273-8.

17. Brits $\mathrm{H}$, Adendorff J, Huisamen D, Beukes D, Botha $K$, Herbst $H$, et al. The prevalence of neonatal jaundice and risk factors in healthy term neonates at National District Hospital in Bloemfontein. Afr J Prim Health Care Fam Med 2018;10:e1-6. [CrossRef]
18. Gunaseelan S, Devadas S, Pai N. Correlation of transcutaneous bilirubin and serum bilirubin concentration in term and late preterm newborns. J Clin Neonatol 2017;6:154-8. [CrossRef]

19. Ho HT, Ng TK, Tsui KC, Lo YC. Evaluation of a new transcutaneous bilirubinometer in Chinese newborns. Arch Dis Child Fetal Neonatal Ed 2006;91:F434-8. [CrossRef]

20. Maisels MJ, Engle WD, Wainer S, Jackson GL, McManus S, Artinian F. Transcutaneous bilirubin levels in an outpatient and office population. J Perinatol 2011;31:621-4. [CrossRef]

21. Rubaltelli FF, Gourley GR, Loskamp N, Modi N, Roth-Kleiner M, Sender A, et al. Transcutaneous bilirubin measurement: a multicenter evaluation of a new device. Pediatrics 2001;107:126471. [CrossRef]

22. McClean S, Baerg K, Smith-Fehr J, Szafron M. Cost savings with transcutaneous screening versus total serum bilirubin measurement for newborn jaundice in hospital and community settings: a cost-minimization analysis. CMAJ Open 2018;6:E285-91. [CrossRef] 